\title{
The natural gas sector needs to be mindful of its sustainability credentials
}

\author{
David A. $\operatorname{Wood}^{\circledR *}$ \\ Co-Editor-in-Chief \\ DWA Energy Limited, Lincoln, United Kingdom
}

\section{Keywords:}

Natural-gas sustainability

gas flaring/fugitive emissions

water usage contamination

fracture stimulation

induced seismicity

enhanced recovery

carbon capture sequestration utilization

Cited as:

Wood, D.A. The natural gas sector needs to be mindful of its sustainability credentials. Advances in Geo-Energy

Research, 2020, 4(3): 229-232, doi:

10.46690/ager.2020.03.01.

\begin{abstract}
:
Despite substantial growth in demand for natural gas, building of infrastructure and prevailing low wholesale prices, some energy-industry stakeholders are now questioning the long-term sustainability of the natural gas industry. This is due, in part, to it being a fossil fuel with associated greenhouse gas emissions, and its very poor long-term historical track record regarding gas flaring and fugitive methane and other light-hydrocarbon gas emissions. However, major environmental concerns have also arisen regarding the development of unconventional natural gas resources using hydraulic fracture stimulation, its large environmental and community impacts, water usage and potential contamination and induced seismic activity leading to increased surface impacts. There are however a number of technological opportunities identified and available for deployment for a number of years that could enable the industry to improve its sustainability credentials. Seriously developing these opportunities could convince public opinion that the natural gas sector should be part of long-term plans to develop and maintain a near-zero emissions energy sector. Most of the identified opportunities are obvious, such as eliminating flaring, improving production efficiency by gaining a better understanding of sub-surface reservoirs and fluid movements, and reducing its surface footprints, carbon capture sequestration and utilization, and more collaboration with the renewables sector to build hybrid power and energy storage plants. It is imperative for the natural gas sector's long-term future that it fully embraces these opportunities and makes them visibly contribute to more eco-friendly energy supply-chain developments.
\end{abstract}

\section{Introduction}

This is written at a time of a glut of global gas supply and low wholesale international gas prices; unprecedented for the twenty-first century. It is a buyers' market, and concerns for many suppliers, particularly regarding the long-distance pipeline and liquefied natural gas (LNG) supply chains, are focused on how to break-even and how to store surplus supply. The current over-supply situation has undoubtedly been exacerbated by the downturn of global economic activity and energy demand due to the global SARS-CoV-2 pandemic. However, an underlying over supply of natural gas available for global trade has evolved over many years. This has been fuelled particularly by rapid growth in North American shale gas and decisions to invest in major new gas LNG and pipeline export supply chains in response to high growth in Asian gas demand over the past decade or so.

On the face of it, global demand for natural gas is robust, and at low prices, is likely to grow over coming years, presenting a potentially bright future for the industry for both suppliers, consumers, midstream infrastructure providers and traders. However, natural gas is not without its challenges, competition and opponents as a long-term baseload source of energy. Over many years, gas has had to compete fiercely with coal, and more recently with renewable energy sources, to establish, grow and maintain a share of the power generation and space heating markets Wood (2016a). Indeed, gas remains squeezed between coal on the one side and renewables on the other in terms of competition in the power generations supply chains.

When gas prices were relatively high, less than a decade ago, coal was out-competing gas on a cost-of supply basis. At

\section{Yandy
Scientific}

Press
${ }^{*}$ Corresponding author.

E-mail address: dw@dwasolutions.com (D.A. Wood). 
the same time, government mandates, policies and subsidies to promote the use of renewable resources to substitute for fossil fuels, where possible, in the major energy consuming markets, due to environmental concerns, has over the years eroded some gas demand in certain markets, particularly in Europe. In North America, low natural gas prices have meant that gas has managed to displace substantial quantities of coal from the power sector over the past decade. At the same time, a desire to improve air quality and reduce harmful atmospheric emissions, has led many Asian countries, particularly around their major cities, to replace coal-fired power plants with more naturalgas and renewable plants, driving rapid growth in pipeline and LNG imports.

Natural gas is a fossil fuel, and because of its relatively high hydrogen: carbon ratio it generates substantially less carbon dioxide emissions than coal when combusted. However, it does contribute to the accumulation of greenhouse gases in the atmosphere and known climate-change issues that result in the long term. This leads many to view gas as the best alternative to other fossil fuels, but only as a short-term bridge to a zerocarbon future, fuelled by renewable energy supply for power generation, space heating and transport. Some governments, particularly in Europe, are setting future energy supply and infrastructure policies and plans with that mindset, and their policy advisers, are promoting that position. For example, the first sentence of a recent report delivered to the European Federation of Energy Traders, entitled "Gas Decarbonisation and Sector Decoupling"(Riechmann and Roberts, 2020), read: "Unabated natural gas likely has a limited long-term role in a decarbonised EU energy system". If such an approach and energy policy becomes pervasive around the world, the ability for natural gas to sustain its growth and sustain its market share will become progressively harder. It is for these reasons that the natural gas sector needs to be mindful of public and government perception of its sustainability credentials and the real issues that fuel some negative perceptions surrounding it.

\section{Sustainability issues for the natural gas industry}

Sustainability, is a widely used term, without a consistently applied definition. Rather than attempt a comprehensive definition of the term, it is, perhaps, more useful to identify and address the issues associated with sustainability concerns pertaining to the natural gas industry. In fact, these issues are quite wide ranging, encompassing:

- carbon dioxide emissions when combusted;

- safety hazards associated with leaks from poorly maintained gas handling infrastructure;

- large gas leaks and associated damage and contamination from high-pressure sub-surface gas storage reservoirs and gas transmission pipelines;

- fugitive methane emissions from poorly cemented and managed wells;

- environmental damage and inefficiencies associated with flaring and/or venting of uneconomic associated gas produced along with oil;

- high consumption of water and chemicals associated with fracture stimulation operations;

- increased risk of micro-earthquakes and seismic damage;

- subsidence issues associated with large scale extraction of gas;

- potential for water contamination (above ground and below) with natural gas' component molecules and/or with well completion/fracture-stimulation fluids;

- produced-water handling associated with coal-seam gas production;

- inefficiencies of intermittent use of single-cycle gas turbines;

- poor recovery of in-place resources from tight reservoirs such as shales leading to more closely-spaced wells being required; and,

- large surface footprints of facilities (wells, separators and flowlines) associated with unconventional gas developments.

Collectively, these issues, some of which the industry has been aware of and failed to adequately address for many decades (e.g., gas flaring) have fuelled negative perceptions of the environmental impacts of the industry as a whole. Merely being a cleaner-burning fuel than coal is not sufficient justification to persuade many long-term energy policy makers that natural gas should be part of plans towards a near-zeroemissions energy future.

Indeed, the environmental consequences of the rapid development of shale resources in North America, albeit focused more on oil than gas, have not helped in this regard. In particular, the increased levels of flaring of associated gas, especially in the Williston Basin (Bakken Shale) and Permian Basin imaged from space for many years (Manthos, 2013). Indeed, the United States has moved rapidly up the rankings of the countries flaring the most natural gas since the onset of large-scale shale exploitation; it reached $4^{\text {th }}$ place in 2017 (World Bank, 2020) with 9.2 billion cubic meters (bcm) of gas flared in that year, behind Russia $(19.9 \mathrm{bcm})$, Iraq $(13.3 \mathrm{bcm})$ and Iran $(11.1 \mathrm{bcm})$. There has been some progress in recent years to reduce gas flaring (World Bank, 2018) but the problem remains a substantial contributor to emissions of greenhouse gases worldwide, and the industry needs to do much more to eliminate it.

In recent years reports of earthquakes induced by fracture stimulation operations have increased in North America (Seismological Society of America, 2019; Skournal et al., 2019), China and the United Kingdom. Most of these are microearthquakes, but some are much larger, e.g., about magnitude 5 in parts of the Sichuan Basin (China) (Inside Science, 2020). Although, it is impossible to say that all of these earthquakes can be attributed solely to fracture stimulation, or that fracture stimulation commonly causes earthquakes responsible for surface damage, the point is that a substantial sector of public opinion believes that they do. The same is true for subsidence induced earthquakes, such as those associated with large-scale gas production from the large, conventional Groningen gas field in the Netherlands, over many years (Vlek, 2019). These have caused substantial damage to buildings, community impacts and political wrangling about that fields 
future. The consequences are that public opinion associates large gas field developments with such outcomes, even though they can, with more careful planning, be avoided.

Water usage, its impacts on water resource availability and its potential contamination of aquifers and surface drainage basins are considered collectively by a range of stakeholders (industry, academia, regulators and communities) to be priority risks to mitigate when planning for and implementing fracture stimulation operations (Murphy, 2020). After many years of research the Environmental Protection Agency (United States Government Agency, EPA, 2016) released its final report on the impacts of hydraulic fracturing on drinking water resources. The EPA found that negative impacts on drinking water can occur in certain circumstances, including spills of fluids at the surface, poor mechanical integrity of the wellbore, discharge of inadequately treated flow-back fluids, storage of wellbore fluids in inadequately lined pits. Although it is possible to mitigate these risks, public perception is that the industry too frequently choses not to do so, or to cut corners to maximize short-term economic benefits, and is selective regarding what it discloses under established sustainability reporting guidelines (IPIECA, 2015).

The natural gas industry clearly has some work to do in order to tangibly improve its environmental and sustainability credentials and to alter public opinion towards a more positive perception. So what needs to be done? Clearly, the challenges facing the industry in each country vary due to their different circumstances (e.g. importer versus exporter) and stages of maturity and development of their infrastructure (Wood, 2016b). It is a combination of complacency and neglect of best practices by many operating and service companies, governments that has led to the natural gas industry's relative poor track record on the flaring, seismic damage and water contamination incidents that have occurred and received highprofile attention by the media in recent years. In order to rectify these problems and work towards restoring its public image the natural gas industry and industry stakeholders, particularly governments, need to take sustainability issues more seriously, and demonstrate to the public that they are doing so. This can be done by striving to address and rectify the issues mentioned by a combination of more robust enforcement of regulations and research and development to seek more effective technological solutions.

\section{Potential sustainable improvements for the natural gas industry}

In fact, there are substantial technological innovations that have already been identified and tested that could be deployed more widely to mitigate the negative environmental footprints and community impacts of the natural gas industry. However, many of these require more investment in field testing, pilot plants and full-scale process evaluations to reduce the risks and costs, and to refine efficiency and technical effectiveness. Some solutions worthy of wider research and development attention are:

- carbon capture sequestration and utilization;

- enhanced recovery from tight gas reservoirs;
- better definition of gas reservoirs to locate sweet spots and reduce the number of wells and surface plant needed to develop them;

- conversion of currently-flared associated gas into power comma liquid fuels, petrochemicals, and hydrogen;

- better well-monitoring and gas-processing plant designs to eliminate fugitive emissions;

- collaboration with the renewables sector to produce low cost of supply hybrid power and energy storage plants providing guaranteed continuous supply;

- improve gas handling efficiency on LNG carriers and floating storage and regasification units;

- developing small-scale gas-fuelled markets (LNG vehicles and bunker fuels);

- developing cheaper and more secure large-scale gas storage options; and,

- collaborating with communities to treat produced and flow-back waters with outcomes that make that water usable by others.

Much progress has already been made in research and development focused on the above technological solutions and opportunities. However, there is scope for considerably more research and innovation. For instance, considering just the subsurface, much uncertainty and lack of deep understanding is associated with unconventional gas reservoirs, including shales, tight sandstones, coal seams and gas hydrates. Better definition of shale reservoirs in terms of multi-scale and fractal permeability analysis of the pore- size distributions (Sheng et al., 2016), lithofacies, three-dimensional modelling (Guo et al., 2015), and more fine-tuned thermal maturity modelling tailored to the kerogens contained in the formations (Wood, 2019) can help to find sweet spots.

Also addressing outstanding sub-surface uncertainties, further development of micro-seismic and naturally induced seismic (Li et al., 2019) could be used to better define the subsurface and surface impacts of hydraulic fracturing. Moreover, enhancing the prediction accuracy of rock properties by Xray tomography of rock cores (Galkin et al., 2015), from well logs with the aid of novel machine learning techniques (Wood, 2020) can also improve sub-surface decision-making. Carbon dioxide adsorption by shale gas (Merey and Sinayuc, 2016) and coal-seams also needs to be much better understood in order to achieve carbon dioxide sequestration in such natural gas reservoir while, at the same time, enhancing natural gas recovery. Gas hydrate saturation and reservoir characterization (Joshi et al., 2019) remains poorly understood but is essentially to control gas recovery from such deposits without destabilizing them.

It is clearly in the industry's own interest to gain the necessary information to be able to commercially exploit at least some of these more sustainable opportunities and demonstrate that it is able to reduce its current environmental footprint along the entire natural gas supply chain.

\section{Conclusion}

It is imperative that the natural gas industry, governments and academia collaborate to find economically appealing so- 
lutions to improve natural gas recovery from reservoirs while reducing the industry's environmental footprint. This could change public opinion to recognize that there are benefits in supporting a long-term future for the natural gas industry, whereby it is able to contribute positively to an environmentally and commercially viable, near-zero, energy future. By doing so, long-term growth of the natural gas industry will more likely be sustained by applying more sustainable and eco-friendly practices.

Open Access This article, published at Yandy Scientific Press on behalf of the Division of Porous Flow, Hubei Province Society of Rock Mechanics and Engineering, is distributed under the terms and conditions of the Creative Commons Attribution (CC BY-NC-ND) license, which permits unrestricted use, distribution, and reproduction in any medium, provided the original work is properly cited.

\section{References}

Environmental Protection Agency (USA). Hydraulic Fracturing and Its Potential Impact on Drinking Water Resources. EPA-600-R-16-236Fb. Office of Research and Development, Washington, DC. December, 2016.

Galkin, S.V., Efimov, A.A., Krivoshchekov, S.N., et al. Xray tomography in petrophysical studies of core samples from oil and gas fields. Russ. Geol. Geophys. 2015, 56(5): 782-792.

Guo, Z., Sun, L., Jia, A., et al. 3-D geological modeling for tight sand gas reservoir of braided river facies. Pet. Explor. Dev. 2015, 42(1): 83-91.

IPIECA. Oil and gas industry guidance on voluntary sustainability reporting. The Global Oil And Gas Industry Association for Environmental And Social Issues. 2015.

Joshi, A.K., Sain, K., Pandey, L. Gas hydrate saturation and reservoir characterization at sites NGHP-02-17 and NGHP-02-19, Krishna Godavari Basin, eastern margin of India. Mar. Pet. Geol. 2019, 108: 595-608.

Li, L., Tana, J., Wood, D.A., et al. A review of the current status of induced seismicity monitoring for hydraulic fracturing in unconventional tight oil and gas reservoirs. Fuel 2019, 242: 195-210.

Manthos, D. Skytruthing the Bakken Shale. September, 2013. Merey, S., Sinayuc, C. Analysis of carbon dioxide seques- tration in shale gas reservoirs by using experimental adsorption data and adsorption models. J. Nat. Gas Sci. Eng. 2016, 36: 1087-1105.

Murphy, R.P. Managing the Risks of Hydraulic Fracturing. Fraser Institute Report. 2020.

Riechmann, C., Roberts, D. Gas Decarbonisation and Sector Decoupling. Frontier Economics. February, 2020.

Rogers, N. The Year Fracking Earthquakes Turned Deadly. Inside Science. 2019.

Seismological Society of America. Studies link earthquakes to fracking in the Central and Eastern US. ScienceDaily. 26 April, 2019.

Sheng, M., Li, G., Tian, S., et al. A fractal permeability model for shale matrix with multi-scale porous structure. Fractals 2016, 24(1): 1650002.

Skournal, B., Brudzinski, M.R., Currie, B.S., et al. Temporal patterns of induced seismicity in Oklahoma revealed from multi-station template matching. J. Seismol. 2019.

Vlek, C. The groningen gasquakes: Foreseeable surprises, complications of hard science, and the search for effective risk communication. Seismol. Res. Lett. 2019, 90(3): 1071-1077.

Wood, D.A. Natural gas needs to compete more innovatively and cooperatively with coal and renewable energies to sustain growth. J. Nat. Gas Sci. Eng. 2016a, 35: A1-A5.

Wood, D.A. The natural gas sector is changing rapidly: Research and technology development remain the keys to overcoming challenges and unlocking opportunities. J. Nat. Gas Sci. Eng. 2016b, 28: A1-A3.

Wood, D.A. Establishing credible reaction-kinetics distributions to fit and explain multi-heating rate S2 pyrolysis peaks of kerogens and shales. Adv. Geo-Energy Res. 2019, 3(1): 1-28.

Wood D.A. Predicting porosity, permeability and water saturation applying an optimized nearest-neighbour, machine-learning and data-mining network of well-log data. J. Pet. Sci. Eng. 2020, 184: 106587.

World Bank. New Satellite Data Reveals Progress: Global Gas Flaring Declined in 2017. 17 July, 2018.

World Bank. Top 30 flaring countries-data (2013-17). 2020. 